\title{
Epidemiology and treatment of adenoid cystic carcinoma of the minor salivary glands: A meta-analytic study
}

\author{
Natalia Martínez-Rodríguez ${ }^{1}$, Isabel Leco-Berrocal ${ }^{2}$, Luis Rubio-Alonso ${ }^{3}$, Oscar Arias-Irimia ${ }^{3}$, José-María \\ Martínez-González ${ }^{4}$
}

\footnotetext{
${ }^{1}$ Collaborator in the Department of Surgery and Orofacial Implantology at the University Hospital of Madrid

${ }^{2}$ Associate Professor of the Master's program in Oral Surgery and Implantology at the University Hospital of Madrid and Associate Professor at the European University of Madrid

${ }^{3}$ Associate Professor of the Master's program in Oral Surgery and Implantology at the University Hospital of Madrid

${ }^{4}$ Professor of Maxillofacial Surgery at the Complutense University of Madrid and Head of the Department of Surgery and Orofacial Implantology at the University Hospital of Madrid
}

Correspondence:

University Hospital of Madrid,

Plaza del Conde Valle Suchil No.9

Madrid 28015, Spain,

hospinatmr@hotmail.com

Received: 13/07/2010

Accepted: $14 / 11 / 2010$

\begin{abstract}
Martínez-Rodríguez N, Leco-Berrocal I, Rubio-Alonso L, Arias-Irimia O, Martínez-González JM. Epidemiology and treatment of adenoid cystic carcinoma of the minor salivary glands: A meta-analytic study. Med Oral Patol Oral Cir Bucal. 2011 Nov 1;16 (7):e884-9.

http://www.medicinaoral.com/medoralfree01/v16i7/medoralv16i7p884.pdf
\end{abstract}

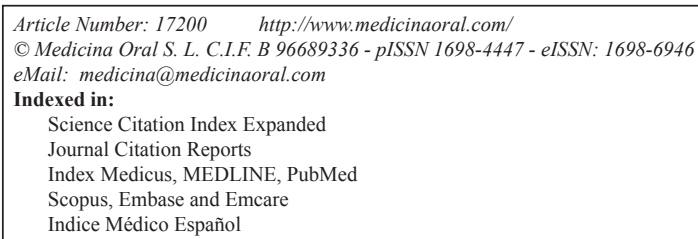

Indice Médico Español

\begin{abstract}
Objectives: To evaluate the epidemiological aspects of adenoid cystic carcinoma (ACC) and to evaluate the different therapeutic possibilities as well as the percentage of survival.

Study Design: A retrospective, meta-analytic, observational study was carried out by selecting a total of 13 articles, which provided a sample size of 263 cases of patients who had been diagnosed with ACC in the minor salivary glands.

Results: ACC was found to be more common among women (56.5\%) and the average age at diagnosis was 55.26 years old. The primary location of the tumor was in the palate in $57 \%$ of the cases, the predominant pattern being cribiform. The treatment of choice was therapy combined with surgery and radiotherapy in $62.7 \%$ of the subjects. The overall survival rate was $70.76 \%$ and $56.76 \%$, at 5 and 10 years respectively.

Conclusions: Early detection of adenoid cystic carcinoma is necessary in order to enable making an earlier prognosis and thus enable a better quality of life for the patient.
\end{abstract}

Key words: Adenoid cystic carcinoma, minor salivary glands, chemotherapy and radiotherapy of the head and neck. 


\section{Introduction}

Adenoid cystic carcinoma (ACC) was first described by Billroth in 1859, using the term "cylindroma", called such because it forms a cross between connective and epithelial elements which make formations that are similar in appearance to cylindromatosis.

This tumor is characterized as presenting a prolonged clinical course, with a slow and progressive growth and a tendency to recur locally as well as metastasize regionally and systemically, sometimes at very late stages. In addition, it presents a strong neurotropism, which is a major route of tumor dissemination. (1)

As far as the prevalence of ACC, it represents a quarter of malignant tumors of the salivary glands, both in the major and in the minor salivary glands, although more frequently located in the minor salivary glands, mainly at the roof of the mouth, which accounts for $31 \%$ of the lesions. (2)

ACC usually appears between the third and ninth decade of life, with a peak incidence in patients between the ages of 40 and 70 years old; however, it does not appear to be predominant in any sex.

As for its histopathology, ACC are distinguished by three different patterns: tubular, cribiform and solid. Contrary to what its name might imply, there are no cystic cavities or mucous, mucinous or gelatinous areas, although macroscopically, there is a mass with a hard consistency, well circumscribed and with a wide base of implantation, usually very attached to adjacent structures while maintaining the integrity of the mucosal surface up to advanced stages.

For the extension diagnosis, computerized tomography (CT) and magnetic resonance (MR) will be the methods of choice, whereas fine-needle aspiration (FNA) or biopsy of the minor salivary glands along with immunohistochemical markers such as the antigen Ki-67 will be used for the histological diagnosis. As for the differential diagnosis, this must include benign and malignant tumors such as pleomorphic adenoma, polymorphic adenocarcinoma, basaloid carcinoma, or mucoepidermoid carcinoma.

For treatment of this tumor, there is not a single therapeutic method that satisfies all needs, which is why an individual planning of the treatment must be made based on the clinical and histological diagnosis, in order to obtain the highest possibilities of healing, local control and reduction of the symptoms, keeping in mind that it is a very invasive and clinically unpredictable tumor.

The treatment must be carried out by different professionals, which makes it a multidisciplinary and multiphasic treatment that includes the following types: surgical therapy, radiotherapy, chemotherapy and combined therapy (surgery and radiotherapy, radiotherapy and chemotherapy), the latter being the treatment of choice. (3)
Thus, the objectives presented in this study were to evaluate the epidemiological aspects of ACC, such as the age of the patient when diagnosed, the sex of the patient, the primary location of the tumor, and evaluate the different therapeutic possibilities as well as the percentages of patients who survive this tumor.

\section{Material and Method}

A retrospective, meta-analytic, observational study was carried out on the results obtained through a bibliographic search in PubMed. The keywords used were: "adenoid cystic carcinoma", "minor salivary gland", "head and neck radiotherapy" and "chemotherapy".

A total of 35 articles ranging between the period from 1997 to 2009 were reviewed, which had to fulfill the following established inclusion criteria:

- Articles that present at least one clinically diagnosed case of ACC

- Articles that contain patients diagnosed with ACC, whose primary location is in the minor salivary glands . Articles that evaluate the treatment used as well as the survival of the patients

Once the aforementioned inclusion criteria were applied, a total of 13 articles were selected, which provided a sample size of 263 cases. (Table 1) These cases were treated by making a descriptive statistical analysis, evaluating the different variables using tables and graphs of frequency and proportions. The following parameters were evaluated:

1. Age: The age of the subjects was recorded at the time of diagnosis, analyzing both their mean age as well as the age range within which they fell.

2. Sex: The patient's sex was established in the percentage and in the ratio, and we evaluated whether there was any correlation between the appearance of the pathology and the patient's age.

3. Primary location: The different locations where the primary tumor could appear and also the frequency of appearance of each one of them was evaluated.

4. Histological pattern: The subjects were classified using category variables, according to the histological type, dividing it into cribiform, tubular and solid; the frequency of appearance was evaluated and correlated with the prognosis.

5. Margins: The existence or non-existence of surgical margins affected was recorded and their possible relationship with the prognosis was evaluated.

6. Treatment: The therapeutic approaches used in the different patients were analyzed, classifying them into the following categories:

. Surgical treatment

- Surgical treatment combined with radiotherapy

. Surgical treatment combined with radiotherapy and chemotherapy

. Radiotherapy

. Chemotherapy 
Table 1. Histological pattern, treatment, surgical margins and metastasis.

\begin{tabular}{|c|c|c|c|c|c|}
\hline AUTHOR/YEAR & $\begin{array}{c}\text { No. of } \\
\text { CASES }\end{array}$ & $\begin{array}{l}\text { HISTOLOGICAL } \\
\text { PATTERN } \\
\end{array}$ & TREATMENT & MARGINS & METASTASIS \\
\hline Cheuk et al. 1999 (4) & 3 & $\begin{array}{l}2 \text { Cribiform } \\
1 \text { Solid } \\
\end{array}$ & Qx +Rt: 3 & $\begin{array}{c}\text { Positive: } 2 \\
\text { Negative: } 1 \\
\end{array}$ & $\begin{array}{l}2 \text { Distant } \\
2 \text { Local }\end{array}$ \\
\hline Avery et al. 2000 (5) & 9 & - & Qx + Rt: 9 & $\begin{array}{c}\text { Positive: } 2 \\
\text { Negative: } 7\end{array}$ & 0 \\
\hline $\begin{array}{l}\text { Hashimoto et al. } 2002 \\
\text { (6) }\end{array}$ & 4 & $\begin{array}{l}3 \text { Cribiform } \\
1 \text { Tubular }\end{array}$ & $\begin{array}{c}\mathrm{Qx}+\mathrm{Rt}+\mathrm{K}: 2 \\
\mathrm{Qx}+\mathrm{Rt}: 1 \\
\mathrm{~K}: 1\end{array}$ & - & 1 Distant \\
\hline $\begin{array}{l}\text { Kokemueller et al. } \\
2004(7)\end{array}$ & 44 & - & $\begin{array}{l}\text { Qx }+ \text { Rt }: 8 \\
\text { Qx: } 36\end{array}$ & $\begin{array}{c}\text { Positive: } 17 \\
\text { Negative: } \\
27\end{array}$ & $\begin{array}{l}11 \text { Distant } \\
16 \text { Local }\end{array}$ \\
\hline $\begin{array}{l}\text { Carrasco et al. } \\
2006(8)\end{array}$ & 1 & Cribiform & $\mathrm{Qx}+\mathrm{Rt}$ & Negative & Local \\
\hline $\begin{array}{l}\text { Triantafillidou et al. } \\
2006(9)\end{array}$ & 22 & - & $\mathrm{Qx}+\mathrm{Rt}: 22$ & - & $\begin{array}{l}2 \text { Distant } \\
2 \text { Local }\end{array}$ \\
\hline $\begin{array}{c}\text { Al-Sukhum et al. } \\
2006(10)\end{array}$ & 1 & Cribiform & Qx & Negative & 0 \\
\hline $\begin{array}{c}\text { Soares et al. } \\
2008(11)\end{array}$ & 1 & Cribiform & $\mathrm{Qx}+\mathrm{Rt}$ & - & 0 \\
\hline $\begin{array}{l}\text { Copelli et al. } \\
2008(12)\end{array}$ & 26 & $\begin{array}{l}7 \text { Cribiform } \\
13 \text { Solid } \\
6 \text { Tubular }\end{array}$ & Qx + Rt: 26 & $\begin{array}{l}\text { Positive: } 9 \\
\text { Negative: } \\
17\end{array}$ & $\begin{array}{l}4 \text { Distant } \\
3 \text { Local }\end{array}$ \\
\hline $\begin{array}{c}\text { García-de Marcos et } \\
\text { al. } 2008(13)\end{array}$ & 1 & Tubular & $\mathrm{Qx}+\mathrm{Rt}$ & Positive & 0 \\
\hline $\begin{array}{c}\text { Bianchi et al. } \\
2008(14)\end{array}$ & 67 & $\begin{array}{l}31 \text { Cribiform } \\
26 \text { Solid } \\
10 \text { Tubular }\end{array}$ & $\begin{array}{c}\text { Qx }+ \text { Rt: } 40 \\
\text { Qx:27 }\end{array}$ & $\begin{array}{c}\text { Positive: } 45 \\
\text { Negative: } \\
22\end{array}$ & $\begin{array}{l}20 \text { Distant } \\
15 \text { Local }\end{array}$ \\
\hline $\begin{array}{l}\text { Agarwal et al. } \\
2008(15)\end{array}$ & 76 & - & $\begin{array}{c}\text { Qx: } 23 \\
\text { Rt }: 2 \\
\text { Qx + Rt: } 51\end{array}$ & - & 6 Distant \\
\hline $\begin{array}{l}\text { Luna-Ortiz et al. } \\
2009 \text { (16) }\end{array}$ & 8 & $\begin{array}{l}6 \text { Cribiform } \\
1 \text { Solid } \\
1 \text { Tubular }\end{array}$ & $\begin{array}{c}\text { No: } 1 \\
\text { Qx: } 4 \\
\text { Qx + Rt: } 2 \\
\text { Qx +Rt+K:1 }\end{array}$ & $\begin{array}{l}\text { Positive: } 1 \\
\text { Negative: } 6\end{array}$ & $\begin{array}{l}3 \text { Distant } \\
8 \text { Local }\end{array}$ \\
\hline
\end{tabular}

Qx: Surgery; Rt: Radiotherapy; K: Chemotherapy; No: Untreated.

7. Metastasis: The appearance of local and distant metastasis, or the lack thereof following the treatment, was recorded and correlated with the survival of the patients.

8. Survival: The percentage of survival of the patients was analyzed at 5 and 10 years in order to evaluate the prognosis of this type of pathology.

\section{Results}

The population studied was variable according to each parameter indicated, as it was not possible to obtain all of the data for each one of the individuals, arriving at the following results:

With respect to the age variable, the 152 patients evaluated at the time of the diagnosis were between the ages of 15 and 87 years old, with a range of 55 years old, the mean age being 55.26 years old.

As far as the patient's sex, in the 184 patients studied, ACC occurs more frequently in women, who account for 104 of the cases and represent $56.5 \%$ of the patients, compared to the $43.5 \%$ or 80 cases which affected men. The proportion between women and men was 1.3 more women than men.

As for the primary location of the ACC in a total of 193 subjects, the most common area was the palate, accounting for $57 \%$ of the cases, corresponding to 110 patients; followed by the tongue, with 31 cases (16\%); in the oral mucosa, with 28 cases (14.5\%); in fourth position was the floor of the mouth, with 16 cases (8.3\%); and lastly, the mandible and lip (Fig. 1).

With respect to the histology, we were able to evaluate 112 cases, the most frequent histological pattern being cribiform, corresponding to 52 patients (46.4\%); followed by the solid pattern, present in $36.6 \%$ of the patients; and a tubular patter in less proportion, accounting for only $17 \%$ of the cases.

On the other hand, the therapy in these patients included different types of treatment, the most common being surgical therapy combined with radiotherapy in $62.7 \%$ of the cases, followed by surgical treatment in $34.6 \%$ 


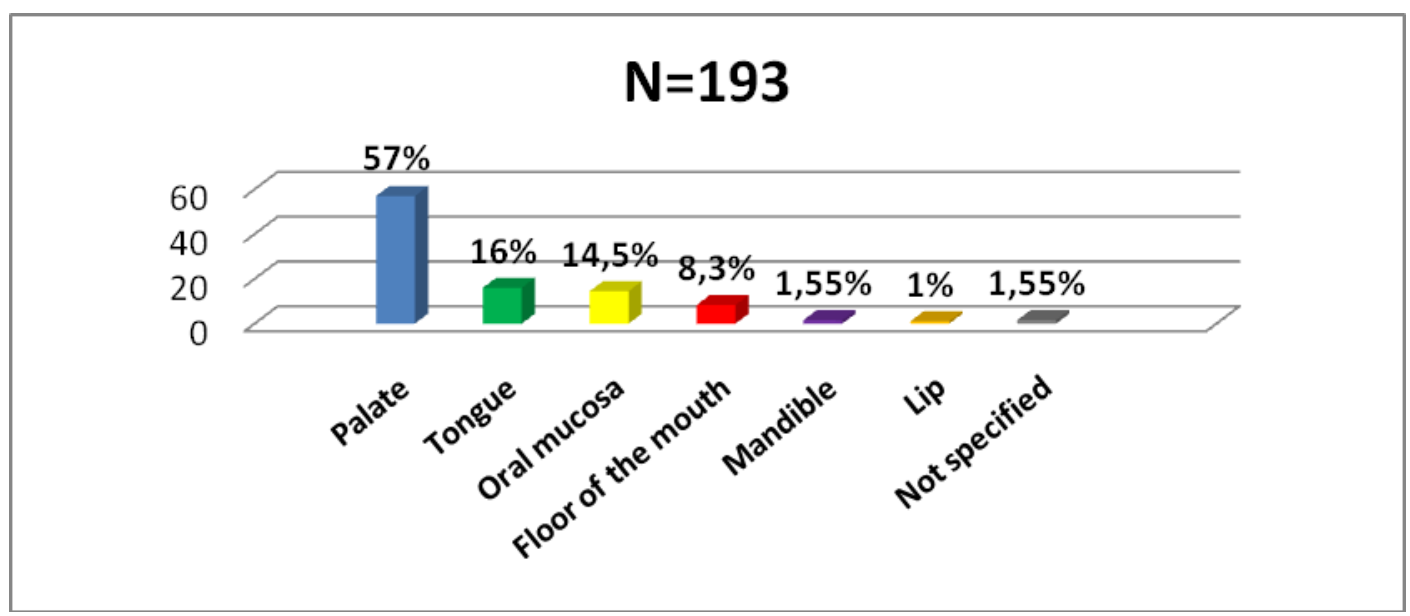

Fig. 1. Primary location of the tumor.

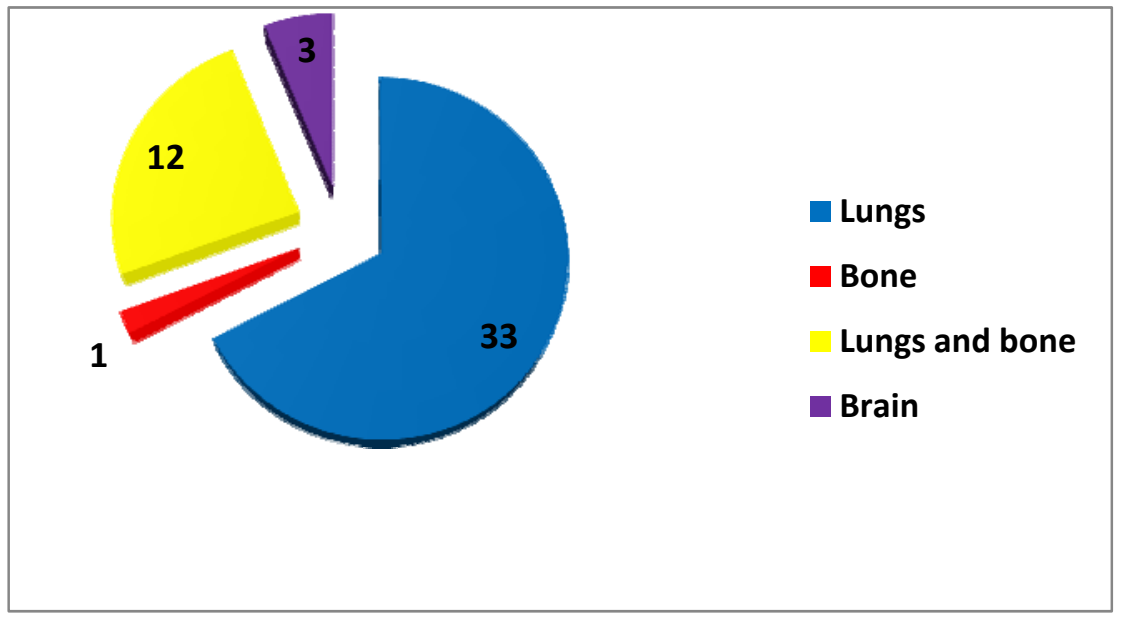

Fig. 2. Location of distant metastases.

of the cases, surgical treatment associated with chemotherapy and radiotherapy in $1.1 \%$ of the cases, only radiotherapy in $0.8 \%$ of the cases, and only chemotherapy with very small, almost insignificant percentages, or no treatment in $0.4 \%$ cases, corresponding to 2 patients respectively.

As for the state of the surgical margins at the microscopic level, there were 159 patients to be analyzed, 82 of which presented margins free of tumors, which represented $51.57 \%$ of the cases, compared to 77 patients whose margins were affected.

Metastasis was evaluated in all of the patients, finding a total of 96 metastases, $48.96 \%$ of which were at the local level, whereas $51.04 \%$ were distant metastases. With respect to the topographic location of the 49 distant metastases, 33 were located in the lungs, 13 in the lungs and bone, 3 in the brain and only one in the bone (Fig. 2).

The overall survival of our series was analyzed in dif- ferent stages as well as in different numbers of individuals. Thus, in the 259 patients evaluated, the survival rate at 5 years was $70.76 \%$, whereas at 10 years, and having analyzed a total of 183 subjects, the percentage drops to $56.76 \%$.

\section{Discussion}

At present, adenoid cystic carcinoma (ACC) accounts for approximately $29.6 \%$ of tumors of the minor salivary glands. It is characterized as presenting a prolonged clinical course, with a slow and progressive growth, and a tendency towards perineural invasion and dissemination through the adjacent nerves and tissues.

With respect to the age of the patient when diagnosed with adenoid cystic carcinoma, authors such as Yih et al. (17) find results similar to our study, establishing a mean age of 58.6 years old. In this sense, authors such as Kokemueller et al. (7) establish a very wide age range, between 15 and 82 years old, whereas others such as 
Hashimoto et al. (6) place the age range between 46 and 64 years old, the latter results being closer to our mean age obtained.

As for the patient's sex, there is a certain predisposition towards females, given that $56.6 \%$ of the patients were women, compared to $43.5 \%$ who were men. However, there are other studies, such as those conducted by da Cruz et al. (18), which challenge the previous results and in which there is predominance among males.

If we evaluate the topographic location of the ACC, authors such as Toida et al. (19) affirm in their study of 10 patients that the most common location is in the palate, representing $70 \%$ of the cases, followed by the oral mucosa, a finding that coincides with the study conducted by Dhanutai et al. (20) and with that obtained in our series, in which the palate was the predominant location. Some authors such as Sequeiros et al. (21) find influence of the histological subtype in the prognosis of the illness, considering the tubular and cribiform patterns to be those with the best prognosis, unlike the solid subtype, which presents a high rate of malignancy and less rate of survival. Thus, the most common histological pattern in our case was cribiform, representing $46.4 \%$ of the cases, followed by the solid and the tubular pattern, with $36.6 \%$ and $17 \%$ respectively, comparing these results with those obtained in the other publications $(14,16,22)$.

Treatment of patients with ACC has generated much interest and debate due to its slow clinical development. Although it is locally aggressive, with high levels of recurrence and late metastasis, ACC is more difficult to resect, which is why surgical treatment alone may fail in the event of recurrence in the surgical margins, as well as in the appearance of distant metastasis (11). In our series, the treatment of choice was a combination of surgery and radiotherapy in 165 of the patients, followed by surgery, and in smaller percentages, that of chemotherapy, radiotherapy or a combination of the three, which are results consistent with those found in other publications $(18,21,23)$. However, authors such as Lopes et al. (24) consider surgical treatment as the usual therapy, limiting the combination with radiotherapy and chemotherapy to cases of cervical lymph node metastasis and perineural invasion, as well as recurring tumors. We only found one patient who was treated with chemotherapy, which represented $0.4 \%$ of our sample. In this sense, Dood et al. (25) evaluate the efficacy of chemotherapy drugs in the treatment of the recurrences or metastases of ACC, obtaining a low response.

The existence of surgical margins free of tumors correlates to a better local control and a better rate of survival, emphasizing the need to perform intraoperative biopsies in order to ensure the surgical margins. However, Sur et al. (26) suggest that the extension of the surgical resection does not affect the overall survival due to the slow growth of these tumors. In our series, $48.47 \%$ of the margins were affected, such that those subjects with positive margins presented less rate of survival $(4,11)$. Only Luna-Ortiz et al. (16) report in a study of 8 patients, that despite finding 6 negative margins, they obtained a low rate of survival.

Distant metastasis of ACC can occur even decades after treatment of the primary tumor and after having achieved an adequate local-regional control, which means low rates of survival. In our case, a greater number of metastases were recorded at the local level, 49 to 47 respectively. As for the location of the distant metastases, $67.35 \%$ were in the lungs, followed by $24.5 \%$ in the lungs and bone, a finding that coincided with the rest of the literature consulted $(18,22,23,27)$.

As far as the overall survival, in our case, it was $70.76 \%$ at 5 years and $56.76 \%$ at 10 years. Similarly, in the study by Maciejewski et al. (28), in which they evaluate $47 \mathrm{pa}$ tients with ACC, they obtained an overall survival rate at 5 and 10 years of $85 \%$ and $45 \%$ respectively.

Therefore, although ACC is a relatively uncommon neoplasm, it is a problematic pathology due to the high tendency towards local recurrence and to the development of distant metastasis, which is why it thus requires close monitoring throughout the life of the patient. For this reason, early detection of the tumor is needed in order to enable early prognosis and a better quality of life for the patient.

\section{References}

References with links to Crossref - DOI

1. Rinaldo A, Shaha AR, Pellitteri PK, Bradley PJ, Ferlito A. Management of malignant sublingual salivary gland tumors. Oral Oncol. 2004; $40: 2-5$

2. Pons Vicente O, Almendros Marqués N, Berini Aytés L, Gay Escoda C. Minor salivary gland tumors: A clinicopathological study of 18 cases. Med Oral Patol Oral Cir Bucal. 2008;13:E582-8.

3. Jansisyanont $\mathrm{P}$, Blanchaert RH Jr, Ord RA. Intraoral minor salivary gland neoplasm: a single institution experience of 80 cases. Int J Oral Maxillofac Surg. 2002;31:257-61.

4. Cheuk W, Chan JK, Ngan RK. Dedifferentiation in adenoid cystic carcinoma of salivary gland: an uncommon complication associated with an accelerated clinical course. Am J Surg Pathol. 1999;23:46572 .

5. Avery CM, Moody AB, McKinna FE, Taylor J, Henk JM, Langdon JD. Combined treatment of adenoid cystic carcinoma of the salivary glands. Int J Oral Maxillofac Surg. 2000;29:277-9.

6. Hashimoto S, Takahashi H, Okamoto M, Yao K, Nakayama M, Makoshi T, et al. Prognostic factors of head and neck adenoid cystic carcinoma: quantitative morphological analysis of 19 cases. Acta Otolaryngol Suppl. 2002;547:93-6.

7. Kokemueller H, Eckardt A, Brachvogel P, Hausamen JE. Adenoid cystic carcinoma of the head and neck--a 20 years experience. Int $J$ Oral Maxillofac Surg. 2004;33:25-31

8. Carrasco Ortiz D, Aldape Barrios B. Adenoid cystic carcinoma of the dorsum of the tongue: presentation of a case. Med Oral Patol Oral Cir Bucal. 2006;11:E417-20.

9. Triantafillidou K, Dimitrakopoulos J, Iordanidis F, Koufogiannis D. Management of adenoid cystic carcinoma of minor salivary glands. J Oral Maxillofac Surg. 2006;64:1114-20.

10. Al-Sukhun J, Lindqvist C, Hietanen J, Leivo I, Penttilä H. Central adenoid cystic carcinoma of the mandible: case report and literature 
review of 16 cases. Oral Surg Oral Med Oral Pathol Oral Radiol Endod. 2006;101:304-8.

11. Soares EC, Carreiro Filho FP, Costa FW, Vieira AC, Alves AP. Adenoid cystic carcinoma of the tongue: case report and literature review. Med Oral Patol Oral Cir Bucal. 2008;13:E475-8.

12. Copelli C, Bianchi B, Ferrari S, Ferri A, Sesenna E. Malignant tumors of intraoral minor salivary glands. Oral Oncol. 2008;44:65863.

13. García de Marcos JA, Calderón-Polanco J, Poblet E, del CastilloPardo de Vera JL, Arroyo-Rodríguez S, Galdeano-Arenas M, et al. Primary adenoid cystic carcinoma of the mandible: case report and review of the literature. J Oral Maxillofac Surg. 2008;66:2609-15.

14. Bianchi B, Copelli C, Cocchi R, Ferrari S, Pederneschi N, Sesenna E. Adenoid cystic carcinoma of intraoral minor salivary glands. Oral Oncol. 2008;44:1026-31.

15. Agarwal JP, Jain S, Gupta T, Tiwari M, Laskar SG, Dinshaw KA, et al. Intraoral adenoid cystic carcinoma: prognostic factors and outcome. Oral Oncol. 2008;44:986-93.

16. Luna-Ortiz K, Carmona-Luna T, Cano-Valdez AM, MosquedaTaylor A, Herrera Gómez A, Villavicencio-Valencia V. Adenoid cystic carcinoma of the tongue--clinicopathological study and survival analysis. Head Neck Oncol. 2009;1:15.

17. Yih WY, Kratochvil FJ, Stewart JC. Intraoral minor salivary gland neoplasms: review of 213 cases. J Oral Maxillofac Surg. 2005;63:805-10.

18. Da Cruz Perez DE, de Abreu Alves F, Nobuko Nishimoto I, de Almeida OP, Kowalski LP. Prognostic factors in head and neck adenoid cystic carcinoma. Oral Oncol. 2006;42:139-46.

19. Toida M, Shimokawa K, Makita H, Kato K, Kobayashi A, Kusunoki $\mathrm{Y}$, et al. Intraoral minor salivary gland tumors: a clinicopathological study of 82 cases. Int J Oral Maxillofac Surg. 2005;34:52832 .

20. Dhanuthai K, Boonadulyarat M, Jaengjongdee T, Jiruedee K. A clinico-pathologic study of 311 intra-oral salivary gland tumors in Thais. J Oral Pathol Med. 2009;38:495-500.

21. Sequeiros Santiago G, Rodrigo Tapia JP, Llorente Pendás JL, Suárez Nieto C. Prognostic factors in adenoid cystic carcinoma of salivary glands. Acta Otorrinolaringol Esp. 2005;56:361-7.

22. Da Cruz Perez DE, Pires FR, Lopes MA, de Almeida OP, Kowalski LP. Adenoid cystic carcinoma and mucoepidermoid carcinoma of the maxillary sinus: report of a 44-year experience of 25 cases from a single institution. J Oral Maxillofac Surg. 2006;64:1592-7.

23. Fordice J, Kershaw C, El-Naggar A, Goepfert H. Adenoid cystic carcinoma of the head and neck: predictors of morbidity and mortality. Arch Otolaryngol Head Neck Surg. 1999;125:149-52.

24. Lopes MA, Kowalski LP, Santos GC, Almeida OP. A clinicopathologic study of 196 intraoral minor salivary gland tumours. J Lopes MA, Kowalski LP, da Cunha Santos G, Paes de Almeida O. A clinicopathologic study of 196 intraoral minor salivary gland tumours. J Oral Pathol Med. 1999;28:264-7.

25. Dodd RL, Slevin NJ. Salivary gland adenoid cystic carcinoma: a review of chemotherapy and molecular therapies. Oral Oncol. 2006;42:759-69.

26. Sur RK, Donde B, Levin V, Pacella J, Kotzen J, Cooper K, et al. Adenoid cystic carcinoma of the salivary glands: a review of 10 years. Laryngoscope. 1997;107:1276-80.

27. Moro Melón M, Manrique Estrada C, Maseda Alvarez E, Pomar Blanco P, Llorente Pendás J, Suárez Nieto C. Adenoid cystic carcinoma of the minor salivary glands. Our experience. Acta Otorrinolaringol Esp. 1999;50:387-91.

28. Maciejewski A, Szymczyk C, Wierzgoń J. Outcome of surgery for adenoid cystic carcinoma of head and neck region. J Craniomaxillofac Surg. 2002;30:59-61. 